\section{Ebola Virus Disease Stigmatization; The Role of Societal Attributes} REVIEW

\section{Abstract}

Globally, persons with diseases like leprosy, tuberculosis, H1N1, SARS or HIV/AIDS have been stigmatized. The ongoing Ebola virus disease (EVD) outbreak in West Africa has been the longest outbreak in the history of the disease and the first outbreak to ever occur in West Africa. The strain of Ebolavirus in West Africa is one of the most virulent strains of the Filoviridae family and case fatalities can be as high as $90 \%$. Treatment of EVD is mainly supportive and societal attributes contribute to stigmatization of the disease and ultimately the spread of the disease. The method used in this study was a search in major databases including PUBMED and Google Scholar. The search phrase used in PUBMED was Ebola stigma. In Google Scholar, the search phrases used included Ebola stigma, EVD, perception of disease, culture and disease. The study also included a review of current events and data from the World Health Organization (WHO) and Centers for Disease Control and Prevention (CDC). In this review, an overview of filoviral hemorrhagic fevers was discussed. The cultural beliefs on the causes of diseases and the stigmatization of infectious diseases in history were examined. In addition, the virulence between severe acute respiratory syndrome (SARS) and EVD were compared. Specifically, it examined Ebola stigmatization and identified societal attributes responsible for the stigma and the implications for controlling the spread. It also points to ways to reduce EVD stigmatization as a way of controlling the spread of EVD. While there is a lot of ongoing research for the cure and control of EVD, little attention is being paid to the role of stigmatization in the control of the disease. Fear is the driving force of EVD stigmatization because EVD is a virulent, fast killing disease that has no cure. Powerlessness is another driving force in stigmatization. The sensationalism in news reporting and the mistrust of the government are factors playing on fear and rumor. Counselling should be provided to the community before survivors of
Titilola T. Obilade MBBS, Ph.D.

Contact information:

Titilola T. Obilade MBBS, MPH, FMCPH, MWACP, MILD, Ph.D.

Senior Education Specialist Learning Sciences and Technology 144J Smyth Hall.

Virginia Polytechnic Institute and State University.

Blacksburg, Virginia, 24061- 0488.

”" obilade@vt.edu 
EVD return home. Survivors of EVD should be counselled before going home. The government should set up a task force on stigmatization and make efforts to regain the trust of the people. Memorials for those that died from EVD should be erected in each of the districts affected. Schools should not be closed for long periods and should only be closed if there is recourse to distance education. Faith based organizations can also use the methods for distance education as a means to encourage their followers.

\section{Keywords}

Ebola virus disease; cultural beliefs; stigmatization; EVD survivors; outbreak; stigma; West Africa; societal attributes, filoviral hemorrhagic fever

\section{Introduction}

Ebola viruses are one of the causative pathogens of the filoviral hemorrhagic fevers [1]. The order Mononegavirales is the taxonomic home of Ebola viruses. Ebola viruses are from the Filoviridae family [2]. Filo viruses are enveloped, non-segmented, negative stranded RNA viruses [1]. In 1979, at a congress on virology and class 4 agents in Johannesburg, South Africa, Filoviridae was proposed as a family name for Ebola viruses and Marburg viruses because of the long filamentous, circular, u-shaped morphological forms of the virions [3]. Filo means thread or filament in Latin [3]. Filo viruses exploit the host cells' defenses to support their own replication [4].

The Center for Disease Control and Prevention (CDC) introduced a classification system for biosafety on handling human pathogens [5]. Biosafety Level (BSL) 4 is the highest biosafety level and filoviruses are classified as pathogens requiring Biosafety Level 4 containment [5]. The infectivity, the severity of disease, the transmissibility and the nature of the work being conducted are assessed before a classification is made [5]. Pathogens that require a Biosafety level- 4 containment are at risk of being potentially transmitted by aerolization and can cause life-threatening disease for which there is no vaccine or therapy $[6,7]$.

Viral hemorrhagic fevers are caused by 23 enveloped RNA viruses from four distinct taxonomic family of viruses [2]: Filoviridae, Arenaviridae, Bunyaviridae and flaviviridae [2]. Filoviridae, Bunyaviridae and Arenaviridae are all negative stranded RNA viruses [2, 8]. Flaviviridae are positive stranded RNA viruses [2, 8]. It is not all the viruses in each family that cause viral hemorrhagic fevers and not all the viruses give hemorrhagic manifestations [2]. Viral hemorrhagic fever viruses have different means of transmission depending on the family [2]. Their specific transmission cycles are maintained by non- human primates, bats, rodents, humans, mosquitoes and ticks [2]. Figure 1 is a UNICEF poster highlighting the potential risk of meats from animals like bats, rodents and non-human primates. 
Figure 1: Poster on prevention of Ebola. Used with permission from UNICEF.

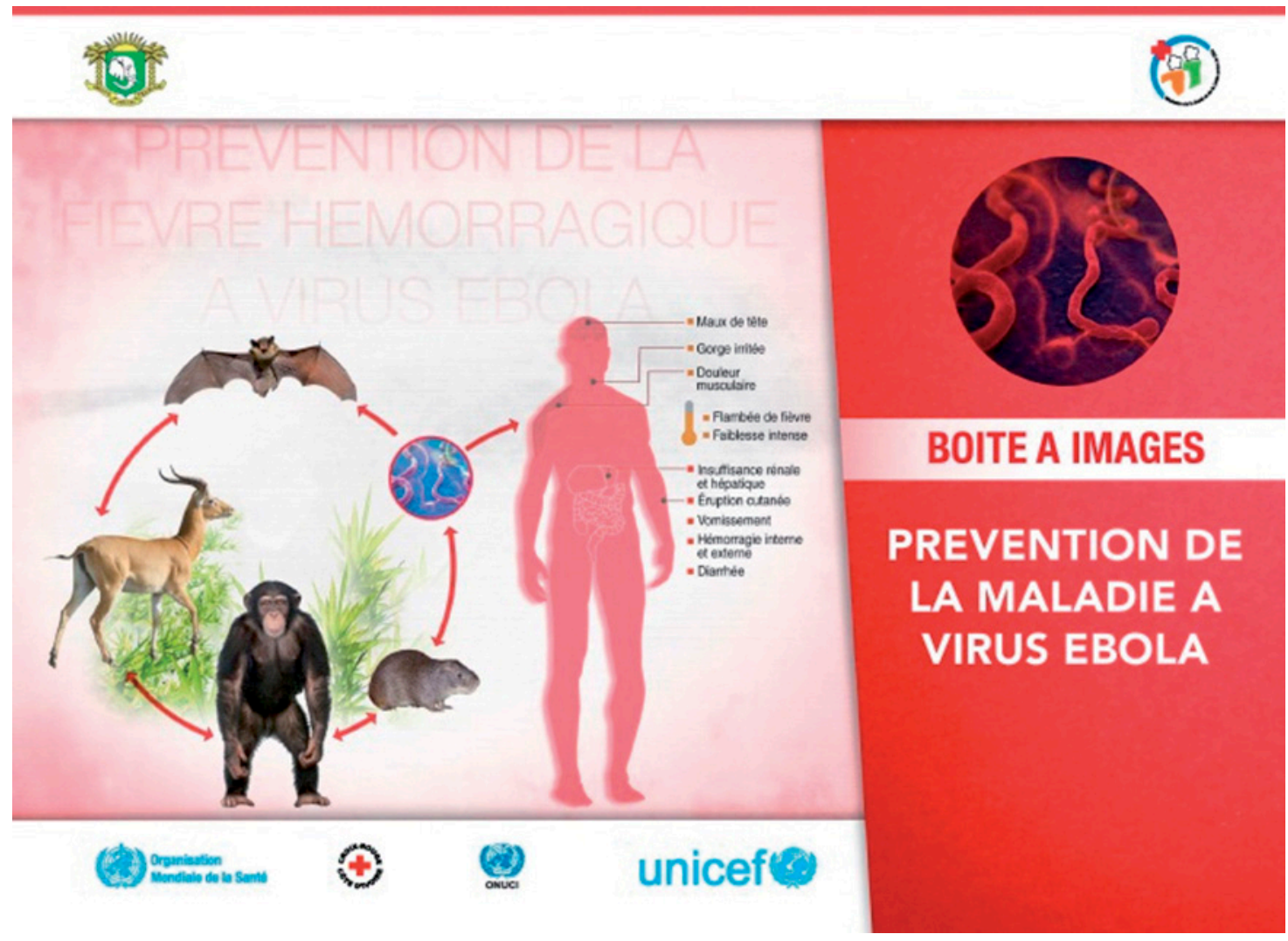

Three virus genera belong to the family Filoviridae. These are Marburgvirus, (MARV) Ebolavirus (EBOV) and more recently, the Cuevavirus [2, 8-10]. Five species of Ebolaviruses have been isolated from the Ebola virus genus. These species are Sudan Ebolavirus (SEBOV/SUDV), Zaire Ebolavirus (ZEBOV/EBOV), Côte d'Ivoire Ebolavirus (CIEBOV/TAFV), Bundibugyo Ebolavirus , (BEBOV/BDBV) and the Reston Ebolavirus (REBOV/RESTV) $[7,8]$. The first three have been responsible for large EVD outbreaks in sub- Saharan Africa [9]. The ongoing outbreak in West Africa is a local EBOV Zaire species variant, slightly genetically distinct from the Ebola virus species that caused the recent outbreak in the Democratic Republic of Congo and therefore supports the argument that it could not have been introduced from Central Africa $[7,9,11,12]$. Marburgvirus and Cuevavirus each have a single species in their genera; MARV species and LLOV species [8, 12].

\section{EVD in Africa}

In 1976, southern Sudan experienced the first outbreak in what was later called Sudan Ebolavirus [13]. A total of 284 people were infected and 151 died [13]. In the same year, northern Zaire, now the Democratic Republic of the Congo (DRC) had its first outbreak of a different species of Ebola virus that was later called the Zaire Ebolavirus [14]. There were 318 infected persons and 280 died [14]. The Zaire Ebolavirus is responsible for the ongoing outbreak in the West African countries [10].

The recently discovered Cuevavirus was detected in dead, infected bats inside caves in Spain [8]. It was named Lloviu virus (LLOV) after the cave from which it was found [8]. Apart from the Reston Ebolavirus that was discovered in monkeys imported from the Philipines, Cuevavirus is the only Ebola virus that was discovered outside Africa and was not isolated from human beings [8]. Figure 2 shows the distribution of the Ebola virus in Africa. 
Figure 2: Illustration of countries in Africa that have had an EVD outbreak (1967-2014). Map drawn by Titilola T. Obilade.
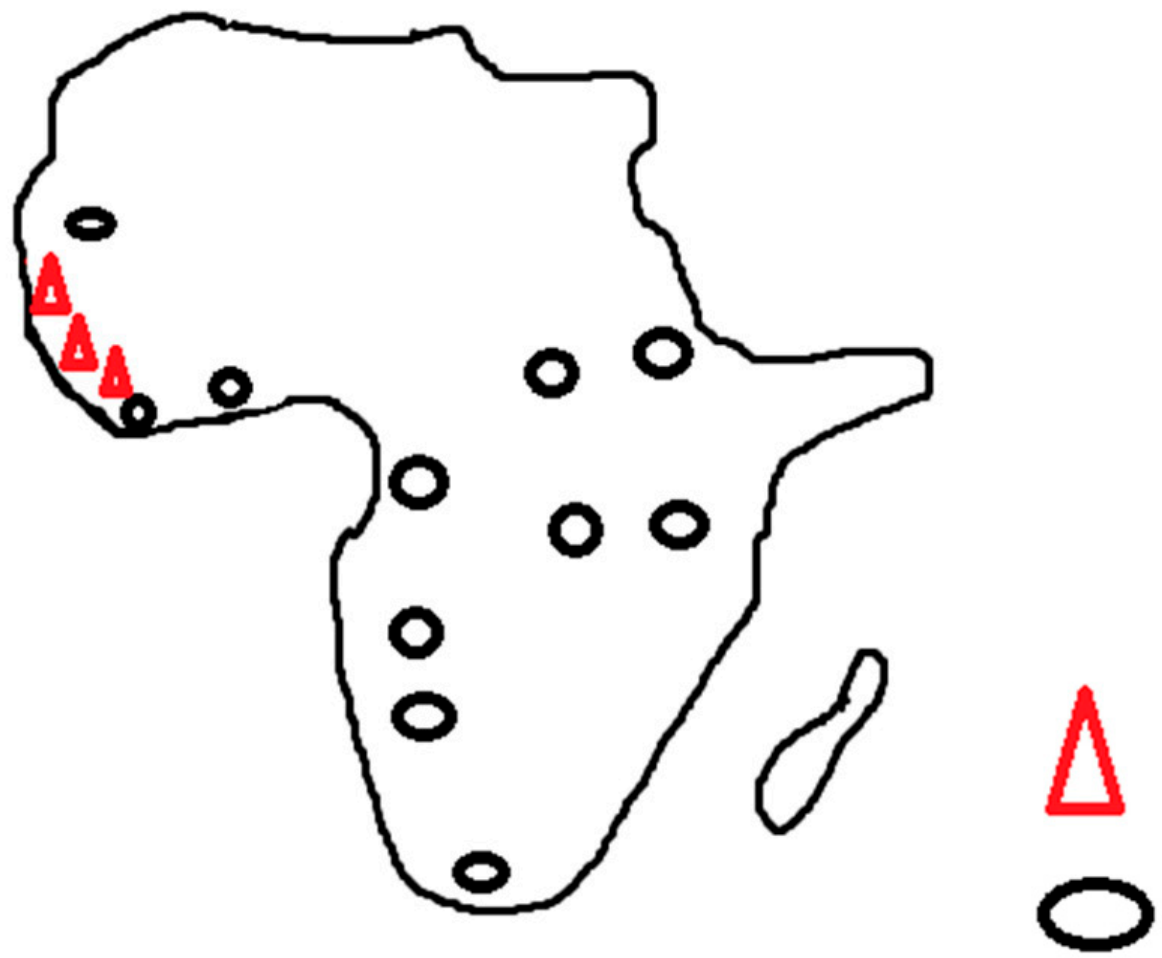

Most affected countries

Other countries

that have had EVD outbreaks in Africa

Three of the species of Ebola viruses have variable case fatality ratios with the highest case fatality ratio being 60-90\% for Zaire Ebolavirus species, 40 $60 \%$ for the Sudan Ebolavirus species and 25\% for Bundibugyo Ebolavirus species [15]. There has only been one reported case of the Tai Forest Ebolavirus (Côte d'Ivoire Ebolavirus) and the virulence of the virus could not be determined $[15,16]$. Limited human studies have been done on the Ebola virus because of biosafety concerns, the remote location of the outbreaks in places with inadequate infrastructure, sporadic and unpredictable timing of the outbreaks and poor filovirus surveillance [7, 15].

\section{Clinical Manifestations of EVD}

The clinical manifestations from the virulence of the Ebola virus may be tempered down by proper intensive care and stringent supportive care [15]. Since 1976, there have been 24 laboratory- confirmed Ebola virus disease outbreaks [7, 17]. The incubation period of EVD is 2-21 days and a mean of 4-10 days [15]. A macropapular rash appears by the $5^{\text {th }}-7^{\text {th }}$ day of illness $[7,15]$. Patients can develop thrombocytopenia and bleed internaIly and externally [12]. Externally, they can bleed from venipuncture sites. They can bleed from the gingiva, from the ears, the conjunctiva, the lungs, the vagina and the gastrointestinal tract $[8,9,15$, 18]. The transmission of the virus is characterized by fever of sudden onset, weakness, chills, malaise, and myalgia [7].

The clinical manifestation of persons infected with EVD is non-specific because the clinical presentation is similar to other endemic diseases in the region $[7,15]$. Diseases that are endemic in the region include Lassa fever, malaria and typhoid fever [7]. Patients that recover from the disease usually suffer from myelitis, recurrent hepatitis, psychosis or 
uveitis [15]. In this current EVD outbreak, patients from Kenema, Sierra Leone that survived from EVD suffer from joint pain, muscle pain, visual problems, headaches and extreme fatigue [19]. On the website for $\mathrm{WHO}$, these manifestations are described as Post Ebola Syndrome [19]. The disease affects all the systems. In a later stage of the disease, there could be shock, convulsions, severe electrolyte imbalance and disseminated intravascular coagulopathy. Death occurs from the disease 6-16 days after the onset of symptoms [2]. Patients that die from the disease, usually die from hypovolaemic shock and multiple organ failure [15]. In the current outbreak in Guinea, there have been more female deaths with a male to female ratio of 41: 59 and a median age of 35 years [9]. The index case in the current outbreak was identified as a 2 year old child from Guéckédou, Guinea but the suspected, introductory animal source has not been identified [15].

\section{Stigma}

Stigma is a social construction that characteristically disenfranchises the stigmatized person or group of persons. Stigma was formerly defined as a physical deformity or a physical blemish until Goffman extended the definition of stigma beyond physical attributes [20, 21]. Goffman's seminal article on stigma classified it into three, broad groups: The first group belonged to those being stigmatized because of their physical deformities like those due to leprosy. The second group belonged to those stigmatized because of perceived or real flaws in their character like ex-convicts, mental disorders and the unemployed. The third group was for those stigmatized according to their tribal affiliations to religion, nationality, sex and race [20].

Some researchers have contended that Goffman's classification is archaic and insufficient to address stigma from health problems in low income countries and stigmas from cross cultural situations [21]. In addition, they contended that Goffman's classifications were broad and ambiguous. A fourth classification that I would add to Goffman's classification is rapid killer disease stigma (RKDS). The Ebolavirus was named after the Ebola River because previously, towns that were named after infectious diseases became stigmatized like Lassa fever named after Lassa, Nigeria. In his narrative on the Ebolavirus outbreak in Yambuku, Zaire (now DRC), Peter Piot explained how the Ebolavirus got named after a river and not after a town because Karl Johnson and the rest of the epidemiologic team did not want the town to be stigmatized. A narrative from Piot's book [22]:

Pierre argued for Yambuku virus, which had the advantage of simplicity; it was what most of us were already calling the disease. But Joel reminded us that naming killer viruses after specific places can be very stigmatizing; with Lassa virus, discovered in 1969 in a small Nigerian town of that name, it had caused no end of problems to the people from that locality. Karl Johnson liked to call his viruses after rivers: he felt that took some of the sting out of geographical fingerpointing. It was what he had done when he'd discovered Machupo virus in Bolivia in 1959, and it was clear that night that he had every intention of doing the same in Zaire. But we couldn't call our virus after the majestic Congo River: a Congo-Crim virus already existed. Were there any other viruses near Yambuku? We charged en masse to a not-very large map of Zaire that was pinned up in the Fométro corridor. At that scale, it looked as though the closest river to Yambuku was called Ebola-"Black River," in Lingala. It seemed suitably ominous. (Piot, No time to lose: A life in pursuit of deadly viruses: WW Norton \& Company; London 2012, pp; 56-57)

\section{Cultural Beliefs on Causes of Diseases}

A leprosy survey conducted in Aceh, Indonesia showed that they believed leprosy could be cau- 
sed by the curse of an angry father, wrath of God for committed sins, breaking of food and other taboos, body fluids and heredity [23]. In Plateau, Nigeria, leprosy was believed to be caused by infection, witchcraft, breaking of taboos and heredity [23]. In Nepal, leprosy was believed to be caused by witchcraft and anger from one of the gods [23].

The people of Guinhangdan in the Philippines believed that illness was caused by sorcerers, witches or spirits. They also believed that until the illness was severe enough to hinder regular activities, they were not ill [24]. The Limbas of Sierra Leone from the Biriwa/Safroko in the south and the Tonko/ Sela from the west believe that leprosy is caused by witchcraft while the Limbas from the north, the Wara Wara believe that people infected with leprosy were witches [25]. Therefore, if a person from the Wara Wara region had leprosy, s/he was blamed but when a person from the south or west region had leprosy, they were pitied because they were considered victims. Leprosy patients from the Wara Wara region are respected as witches and houses are built for them. They also believed that leprosy was not transferred because only witches could have leprosy. The Tonko/Sela from the west and the Biriwa/Safroko from the south expel their leprosy patients [25].

In the United Kingdom, 45 study participants were stigmatized because people thought their lung cancer was caused by smoking even though lung cancer can be caused by other factors [26]. In another study conducted in the United Kingdom, researchers interviewed 1,620 women. The women were asked to rate how much they would blame patients with breast cancer, cervical cancer, bowel cancer, lung cancer, leukemia and chlamydia. The participants attributed the most blame to lung cancer and chlamydia. Leukamia and breast cancers were attributed the least blame [27]. Diseases that were seen as having behavioral origins were blamed on the infected persons. When African Americans from northern California were surveyed using a close-ended questionnaire on their beliefs on cancer, $65 \%$ of the respondents believed that cancer was a death sentence and more than 75\% believed that during surgery, cancer could spread through the air [28].

In western Nigeria, onchocerciasis (nàrun) is believed to be caused by worms residing in the body. It is believed that worms normally reside in the body to induce fertility but that excess of the worms could cause onchocerciasis (nàrun). It is also believed that the hitching associated with onchocerciasis (nàrun) was caused by eating certain types of vegetables, cheese and that it could be caused by not bathing frequently. The local name for onchocerciasis in western Nigeria is nàrun. Nàrun is from the phrase iná òòruǹ (fire from heaven). They also belief that nàrun can spread from the water that comes out of the onchocercial skin lesion [29].

A study conducted in Zambia to identify causes of stigma related to tuberculosis and other opportunistic infections from HIV showed that judgment, blame and shame, fears of tuberculosis transmission and government health policy and practice on tuberculosis were identified as causes of tuberculosis stigma [30]. The study showed that patients that were not infected with HIV but had tuberculosis did not feel stigmatized as much as those that were infected with tuberculosis and had HIV [30]. In the government clinics, patients that had tuberculosis had a separate waiting area which made it easy to identify patients that had tuberculosis. The people also believed that tuberculosis that was not associated with HIV/AIDS was caused by smoking tobacco or marijuana, drinking home brewed liquor, working in the mines or by abortion. They also believed that tuberculosis could be caused by a person's stubbornness. Further, they believed that stepping on the sputum or faeces of an infected person could cause the disease. Passing a place where an infected tuberculosis patient had urinated was also believed to cause tuberculosis [30]. 
In a separate study conducted in South Africa, the participants believed that tuberculosis was caused by breaking cultural taboos like not abstaining from sex after the death of a family member. Further, the participants believed that tuberculosis could be caused by environmental pollution, excessive alcohol consumption and having sex with a woman who has just had a spontaneous abortion. In addition, they believed that patients receiving treatment for tuberculosis should abstain from sex [31].

\section{Stigmatized Infectious Diseases in History}

Leprosy has been a source of stigmatization since human history [32]. Globally, patients infected with leprosy were isolated and mandatorily quarantined for the rest of their life. They were treated in leprosariums. Barriers that added to the burden of stigma were removed after an effective treatment was discovered. Leprosariums around the world began to close although some countries still keep leprosy infected patients in leprosariums [33, 34].

In 1946, patients with leprosy were allowed to vote. In 1947, leprosy was officially called Hansen's disease to reduce the stigma attached to being called a leper [35]. In 1947, The Public Health Service removed leprosy from the list of quarantinable diseases that required a travel permit. The other diseases on the list of qurantinable diseases are cholera, diphtheria, infectious tuberculosis, plague, yellow fever, small pox and viral hemorrhagic fevers.

Severe acute respiratory syndrome was added to the list of quarantinable diseases in 2003 [36].
All the quarantinable diseases are included in the list of communicable diseases of public health significance. HIV infection was added to the list of diseases of public health significance in 1987 [37]. The Human Immuno Deficiency Virus infection was among the list of communicable diseases of public health significance until 2010. The other diseases on the list of diseases of public health significance are active tuberculosis, infectious syphilis, gonorrhea, infectious leprosy, chancroid, and lymphogranuloma inguinale.

In 2009, during the H1N1 influenza outbreak, a country in East Asia quarantined visiting nationals from a North American country even when the visiting nationals were not sick because of the perception that the visiting nationals had the H1N1 influenza flu [38]. The index case for H1N1 was from that North American country [38]. The estimated number of deaths due to the 2009 H1N1 influenza flu in the USA was 12,469 [39].

The 2002-2003 SARS outbreak infected 8096 persons between November 12002 and July 31 2003 and 774 people died [40] In the current EVD outbreak, 19,497 persons were infected between December 2013 and December 24, 2014. As of December 24, 2014, 7,588 people had died [41]. Table 1 shows that the case fatality ratio for SARS is $9.6 \%$ and $38.9 \%$ for EVD. The World Health Organization Ebola Response Team estimates the case fatality of the EVD to be $70 \%$ [42].

Table 1. Comparison of Case Fatalities between SARS 2002/2003 Outbreak and the Current EVD Outbreak.

\begin{tabular}{|l|c|c|c|c|c|}
\hline $\begin{array}{c}\text { Infectious } \\
\text { Disease }\end{array}$ & $\begin{array}{c}\text { Maximum Incubation } \\
\text { Period }\end{array}$ & $\begin{array}{c}\text { Total Number of } \\
\text { Cases Including } \\
\text { Suspected Cases }\end{array}$ & $\begin{array}{c}\text { Time Period of } \\
\text { Total Cases }\end{array}$ & $\begin{array}{c}\text { Number of Case } \\
\text { Fatalities }\end{array}$ & $\begin{array}{c}\text { Number of Case Fatalities/ } \\
\text { Total Number of Cases in } \\
\text { Percentages }\end{array}$ \\
\hline SARS & $10[40]$ & 8096 [40] & $\begin{array}{c}1 \text { Nov 2002-31 } \\
\text { July 2003 [40] }\end{array}$ & $774[40]$ & 9.6 \\
\hline EVD & $21[41]$ & 19497 [41] & $\begin{array}{l}\text { Dec 2013-24 } \\
\text { Dec 2014 [41] }\end{array}$ & 758 [41] & 38.9 \\
\hline
\end{tabular}

[40] and [41] are listed in the references at the end of the manuscript. 
Leprosy, HIVIAIDS, tuberculosis, H1N1 and SARS instill a lot of fear in people because of what society has attributed to these diseases and those that get infected with any of these diseases are stigmatized. The attributions to these diseases are not without merit. Leprosy can leave physical deformities when not treated early. Medical textbooks describe the faces of those infected with leprosy as lion-like faces or leonine faces because of the way the face looks after it has been destroyed by leprosy. Physical deformities from leprosy are a source of stigmatization because they cannot be hidden and are easily identifiable [43]. H1N1 was a pandemic in 2009 but it is no longer a pandemic even though it is still infecting people today. It is now considered a seasonal flu [44].

The SARS outbreak lasted for about eight months and during that time, the overall estimated case fatality for SARS was $14 \%$. The case fatality could be less or higher depending on the age of the patient and other factors [40]. Approximately eight months after the index case in the current EVD outbreak, the overall case fatality rate was 52\% [45]. The introduction of multidrug therapy has reduced the incidence of leprosy. Anti-tuberculosis therapy is effective in treating tuberculosis if the treatment regimen is adhered to. The seasonal influenza vaccine can be taken to prevent H1N1 influenza. Antiretroviral therapy has been successful in reducing the disease burden of HIVIAIDS. There is no vaccine for SARS but it was eventually controlled during the 2003 outbreak. People infected with Leprosy, tuberculosis, H1N1, HIVIAIDS and SARS used to be severely stigmatized but as soon as an effective management became established, the stigma associated with them decreased markedly.

However, with the Ebolavirus there are still many mystifying areas. When the symptoms first appear, they can be misdiagnosed as malaria, typhoid fever or any tropical disease that is endemic in the regions that have been hit by the EVD. Further, the presentation in each patient is variable. Some pa- tients present with bleeding and some do not. The case fatality is high. There is no known cure and the disease outcome is uncertain despite palliative treatment. The source of the animal infection and route of infection of the index case in the current EVD outbreak remain unknown, although several plausible causes have been suggested [9].

The virulence of the disease is such that it can wipe out entire families [22] and has left many children as orphans [22]. It has threatened the fabric of the culture of the affected nations and it has depleted their meagre resources [46-48].

Public gatherings have been banned because of the risk of spreading the disease. Doctors, nurses and other health care workers have succumbed to the disease accentuating understaffed and over stretched manpower. The management of high consequence pathogens includes early reporting, contact tracing, isolation, quarantine, rumor and stigma management. Although the 2003 SARS spread to 24 countries the death toll was less than in the present EVD outbreak because of the implementation of early management protocols [49].

The index case of the present EVD outbreak was reported to have occurred in Guéckédou, Guinea in December 2013 [42] but it was not until March 12, 2014 that Médecins Sans Frontières in Guinea was alerted [9]. The outbreak was initially graded as a level 2- emergency by the WHO Emergency Management Team but on 24 July, 2014 it was regraded to 3 because of the severity of the outbreak and the incident of a Liberian traveler infected with EVD traveling to Nigeria $[50,51]$. The declaration of Public Health Emergency almost nine months after the EVD index case occurred severely imparted the outcome in the present outbreak.

\section{Culturally Perceived Causes of EVD}

The delay in reporting rapid killing diseases contributes to the spread of the disease. In addition, a virulent disease that kills within a short period from the time of clinical manifestation and seems to de- 
cimate anyone in contact with an infected person fuels rumor, stigma and mistrust of the government. Ebola virus disease stigmatization is undermining the control of the disease. In the prevention and control of EVD, the role of stigmatization must be considered.

When a disease defies explanation and rapidly sometimes takes away the life of the individual or disfigures the physical appearance, as in leprosy, people across different cultures tend to develop certain beliefs to explain the cause of the disease. In a medical anthropological study on EVD in response to the 2003 Republic of Congo EVD outbreak [52], sorcery and the La Rose Croix Organization (an organization sponsored from abroad) were believed to be responsible for EVD outbreak. The Congolese believed that EVD was caused by a spirit or an object. They did not believe that EVD was caused by contact with sick individuals. They also believed that members of the La Rose Croix sent EVD to their victims. As the disease progressed and the people noticed that EVD infected anyone including those they perceived were the cause of the disease, the belief that it was caused by sorcery waned and they believed it was caused by the air or the wind.

There was also a political economic explanation to their beliefs. There was a history of colonialism and exploitation by Euro Americans before the outbreak. Some teachers were killed because the people thought they were agents of the La Rose Croix organization. The people believed that the outbreak was caused by Euro-Americans to stop them from hunting. The Euro- Americans had invested in the Natural Parks and the local people believed that discouraging them from hunting was enhancing the investments of the Euro-Americans [52]. Further, animals were a potential source of EVD and the people had been advised not to hunt certain animals. The poster in Figure 1 shows animals as a potential source of EVD. They also believed that the animals were poisoned by the Euro-Americans in an effort to control poaching on the animals [52].
A similar study conducted in northern Uganda on the perceived cause of EVD showed that the Acholi people had three models to explain the cause of EVD; the biomedical model and two indigenous models. The biomedical model followed the standard procedure for treating illnesses like malaria. The two indigenous models were beliefs that EVD was caused by Gemo or yat. Gemo was caused by a bad spirit and yat was caused by poison. They also believed that disrespect to the gods could bring Gemo. Although the belief was not scientific, the treatment of Gemo had similarities to the scientific management of isolating the EVD patient [53].

Traditionally, they bury the dead near their homes but if the disease was believed to be caused by Gemo, the burial took place further away from the home. They were afraid to go to the hospital because if they died at the hospital, their body would not be buried near their homes but would be buried in the airfield. The fear of going to the hospital was also heightened because they believed the Euro-Americans were placing the dead in body bags to sell their "body parts" [53].

\section{Societal Attributes and Implications of Ebola Virus Disease Stigmatization}

Ebola virus disease survivors are being stigmatized. Family members and health workers treating people with the EVD are stigmatized. During a previous outbreak in Uganda, the husband of a man whose wife died from EVD committed suicide because of the stigmatization [53]. Survivors of EVD lost their livelihood [53]. They were abandoned by their spouses. Their children were instructed not to touch them [53]. They were not welcome in the market. Survivors of EVD and family members of the EVD survivors were not allowed to use the same well as the rest of the community [53]. The women were more stigmatized than men and were rejected whenever they walked in the neighborhood [53, 54]. Health care workers working with EVD patients were also shunned by their family members. In a 
study conducted in Gulu, Uganda, Kikwit, Democratic Republic of Congo and Republic of Congo, nurses working with patients infected with EVD and people living in communities with EVD were stigmatized and called Ebola people [54].

During an EVD outbreak in The Republic of Congo, four school teachers were murdered because the community was suspicious of their links to foreign health workers helping to control the disease $[52,54]$. In the current EVD outbreak, eight health workers on a health education campaign were attacked and killed by members of the community [55]. Rumors have been generated about the spread of EVD. These rumors eventually alienate the people from the government. The communities affected with EVD prefer to believe the rumor rather than the government. This element of mistrust prevents the people from reporting cases of EVD which in turn prevents contact tracing and the disease escalates to exponential proportions.

Stigmatization has also magnified the spread of the disease because those infected are afraid of going to the hospital and be known as an Ebola patient. In addition, they are afraid of going to the hospital because if they die, their corpses would not be returned to their families [53]. Funeral rites are deeply rooted in these communities and their burial practice has been a major source of spread of EVD. As part of their burial practice, the dead body is washed and dressed by the paternal aunt or a female member from the paternal side [53]. Part of the burial ceremony allows male and female members to touch the body of the deceased [53]. They also wash their hands in a communal bowl [53].

While a lot research has been devoted to the cure for EVD, there is a paucity of recent research on the role of Ebola stigmatization in the control and prevention of EVD. The results from the evaluation of the role of Ebola stigmatization can be used to control the spread of the disease. On the 25th of October 2014 when the word Ebola was entered in
PUBMED, it brought up 2149 search results. When the search phrase Ebola stigma was entered in PUBMED, it brought up only two published articles as shown in Figure 3. The articles were published in 2012 and in 2002 [56, 57].

There is a need for more research on how to ameliorate stigmatization from rapid killing infectious diseases because stigmatization will discourage those with the disease from reporting thereby escalating the disease. Further spread of the disease would increase fatalities, fear and rumors until it becomes a vicious cycle. Stigmatization leads to an increase in the morbidity on EVD survivors, their families and on their community members.

\section{EVD Stigmatization}

For the purpose of this paper, Ebola stigmatization means the social disenfranchisement of a person or a group of persons because of the stigmatizers' perception, belief or fear that the stigmatized person or persons can no longer belong to their community because of their associations with the EVD. A survivor of EVD, their community member, their family member, a health worker or an indigene from an EVD endemic country are considered to have associations with EVD. On the international level, in order to protect their countries from EVD, several countries have banned travel from the three most affected countries. In Africa, citizens from other African countries not affected by the EVD have stigmatized citizens from the affected nations. In the 2015 Africa Cup of Nations, even though Morocco was initially slated to host the game, it did not because of fears over EVD [58].

Table 1 shows the fatality of EVD to be about four times that of SARS. EVD and SARS are both caused by viruses. They both spread rapidly and can quickly cause death depending on several factors. Infections with both diseases require barrier nursing. They are both highly contagious. They are both sources of stigmatization. However, apart from the geographical locations of the infectious global threat of SARS 
Figure 3: Screen shot of search results when Ebola stigma was entered in the search box on October 25, 2014.

\section{PubMed}

- ebola stigma|

ه RSS Save search Advanced

Display Settings: $⿴$ Summary, Sorted by Recently Added

Send to: $\square$

\section{Results: 2}

\section{"A time of fear": local, national, and international responses to a large Ebola outbreak in Uganda.}

1. Kinsman $\mathrm{J}$.

Global Health. 2012 Jun 13;8:15. doi: 10.1186/1744-8603-8-15.

PMID: 22695277 [PubMed - indexed for MEDLINE] Free PMC Article

Related citations

\section{An outbreak of Ebola in Uganda.}

2. Okware SI, Omaswa FG, Zaramba S, Opio A, Lutwama JJ, Kamugisha J, Rwaguma EB, Kagwa P, Lamunu M.

Trop Med Int Health. 2002 Dec;7(12):1068-75.

PMID: 12460399 [PubMed - indexed for MEDLINE] Free Article Related citations

being different from the geographical locations of the EVD, the responses to SARS outbreak which succeeded in bringing SARS under control in eight months were different from the responses to the present EVD outbreak. South Africa was the only African country that had a case of SARS. It was a single, imported case and the patient died [59]. Since SARS was not prevalent in Africa, it would prove challenging to speculate on how SARS control might have fared if it had spread to more countries in the continent.

The case fatality ratio for EVD in the current outbreak is $70 \%$ [42]. Therefore, the people in EVD affected countries have a real and palpable fear of the EVD. There fears are substantiated by several factors. There is no licensed cure for EVD. The disease has not spared any social class. It has not spared the revered traditional healers. Among the people in the affected nations, some of their cultural beliefs give room to suspicion on the cause of the disease as could be seen when some teachers were murdered because of their suspected ties to La Rose Croix [52]. Traditional beliefs are very difficult to overcome. Further, in their lives, they have seen or known someone struck with the EVD. Even when they survive, they are left in a deficit state of health [60]. The WHO calls these myriad of deficits Post Ebola Syndrome [60]. In a case fatality of 70 $\%$ if a household of 10 people all get EVD, and assuming they all go to hospital, only 3 persons are likely to return home alive. Their suspicions of the hospital and government are further heightened when the corpses are not returned to the family. Therefore, there is a widening distrust and an increasing suspicion between the people and the hospital that they see as part of the government. This widening distrust is only waiting to erupt and it erupted in some cities when some health workers were attacked and killed by the community members [55]. 
The Human Development Indices in these affected countries are among the last 13 out of 187 countries [61]. When a survivor returns from the hospital, they see a situation that they can control or at least a situation where they want to control because they have not been able to control everything else around their health. The EVD survivors often return home weak and sometimes with loss of vision in the eyes or other forms of morbidity [60]. The communities affected with EVD have not been able to control the associated deaths. They have not been able to control what happened to them in the hospital because those who die in the hospital are buried in unmarked graves contrary to their beliefs. In a published research in this present outbreak, informed consent was not taken from the patients before their clinical data was used in data analysis [9] because that research was in response to a public health concern to the EVD outbreak. However, the EVD patients and EVD caregivers may be suspicious about the data being collected. When a survivor returns, they try to regain some control over their already disturbed lives by preventing the EVD survivor or anyone associated with him/her from their community.

The fear of being stigmatized with any association with EVD, the perception of risk, the sensationalism in news reporting from the media, the hysteria surrounding EVD around the world, the number of those taken to the hospital and dying there being more than those who recover, the inability to perform burial rites, the perceived irreverence of their cultural rites, the fatalities witnessed, the morbidity that is sometimes associated with recovery from EVD, the helplessness of the people, chronic poverty, inadequate sanitary practices, struggling health care systems, poor or nonexistent infrastructure, the cultural belief of the prevention and cause of the disease, the lack of trust between the people and the government and the helplessness of the government are some of the societal attributes contributing to EVD stigmatization.
The upward trajectory of cautionary measures by the CDC is also an added point of fear of EVD. After one of the nurses that treated the index case of EVD in the USA got infected, the CDC revised their protocols ensuring that no parts of the body were exposed. Eventually, two of the nurses that treated the index case of EVD in the USA got infected and they both recovered.

While it may be easy to cover up completely in personal protective equipment in a temperate region, it might not be so in tropical regions. The health care workers in West Africa are aware of the risks and their fears could be heightened by the development of EVD from nurses that looked after the index case in USA where there was access to better infrastructure to manage the EVD patient.

Countries are giving financial support without sending the manpower to come to the affected countries because there are not enough clinicians willing to engage in basic care of EVD patients in remote locations that also have severe infrastructural challenges $[62,63]$. The infrastructural challenges become more apparent when the two nurses that contracted EVD while in the USA fully recovered [64].

\section{The Way Forward}

The fears coming from different facets lead to mistrusting the government. The government needs to gradually earn back the trust of the people. The way forward has been divided into different levels.

Community level: Counselling should be provided to families that have had a patient with EVD. Before an EVD survivor is sent back home, s/he should be counselled. Similarly, the family should be counselled before the EVD survivor reenters the community. In Firestone district, Liberia, discharged EVD patients were reintegrated back into the community by award of a medical certificate of wellness, a celebration of the return of the EVD survivor and presentation of a solidarity package [65]. The solidarity package 
consisted of a mattress, a mosquito net and other essential household items. At the reintegration ceremony, the EVD survivor was allowed to talk about his/her experience and the event was broadcast on radio and recorded for future educational purposes. In addition, members of the community participated in preparing for the reintegration ceremony [65]. Successful reintegration programs similar to those in Firestone district, Liberia could be replicated. There should be individual ownership and community ownership in the control and prevention of EVD [66]. Sanitation should be improved at individual and community level.

Governmental Level: The Governments of the three most affected countries should set up a Task Force to manage EVD stigmatization. In an effort to reduce EVD stigmatization, the Task Force should broadcast meetings of EVD survivors interacting with someone whose face is well known by the people. The prominent person could be the president, the vice president, a popular musician, a religious leader, a popular actress/actor or a popular athlete. While shaking of hands, fist bumping and elbow bumping should be discouraged, the EVD survivor and the chosen prominent person should be seen interacting so as to dispel the fears that the EVD survivor is a harbinger of the disease. Non-touch techniques of greeting can be developed.

Health education and rumor dispelling should be included in the management of stigmatization. Attention should also be paid to people with special needs. People with special needs especially those that are completely blind may find it challenging to navigate through the demands necessitated by the EVD outbreak especially when they depend on touch for performing regular tasks and touching should be avoided. Those who use wheel chairs and walking sticks should be assisted in cleaning them every day.

Efforts should be made to increase the confidence of the people in the health care system. Protocols should be developed for basic medical care at the individual and community level. The government should plan ahead for future outbreaks and should collaborate with governments of other African nations that have had several outbreaks of EVD. In addition, they should collaborate with Nigeria and Senegal, two African countries that successfully stopped the transmission of EVD in this current outbreak. The Democratic Republic of Congo just had a recent EVD outbreak unrelated to the outbreak in West Africa and on November 22, 2014, the WHO declared DRC free of EVD transmission. The past experiences that DRC has had in managing several EVD outbreaks played a role in the successful termination of the outbreak [67]. Basic amenities like potable water, refuse disposal and toilets should be provided to enable the people to practice effective, personal hygiene.

Individual and Community Ownership Level: Prevention is a safer option than waiting for the disease to commence before treating. Therefore, individuals and communities should take ownership in the prevention and control of the disease [66]. They should be responsible for doing everything within their purview to prevent the disease. They should monitor their body temperatures twice daily at temperature stations provided by the government. They should practice safe personal hygiene on a daily basis. They should immediately self-isolate as soon as they notice they have a raised temperature. Community ownership comes into play when the community members support the individual in self isolation by providing food and other necessities before health workers arrive. Prominent and respectable members of the community should be incorporated in health education to respectfully debunk myths around EVD. Village Health Workers are members of the community and can be trained on basic protocols on what to do if a member of the community gets infected.

Educational Level: Since schools have been closed, the government can make use of distance lear- 
ning by broadcasting educational programs through the radio, the television, mobile phone devices and the internet when the internet is accessible [68]. Nomadic children use distance learning tools to access education and the governments of the affected countries may consider distant learning resources especially in densely populated areas [68]. However, schools are a great resource for health education in dire situations like in the current out- break and should only be closed if there is access to distance education. Teachers are a good resource and can be trained to teach their pupils about personal hygiene and debunk the myths surrounding EVD. Similarly, since public gatherings are discouraged, faith based organizations may educate their followers against stigmatization through the radio, the television, the internet and mobile phone devices. Posters like those in Figures $\mathbf{4}$ and $\mathbf{5}$ are a

Figure 4: Poster on Ebola Virus Used with Permission from UNICEF.

\section{PROTECT YOURSELF PROTECT YOUR FAMILY PROTECT YOUR COMMUNITY \\ from theEbola virus}

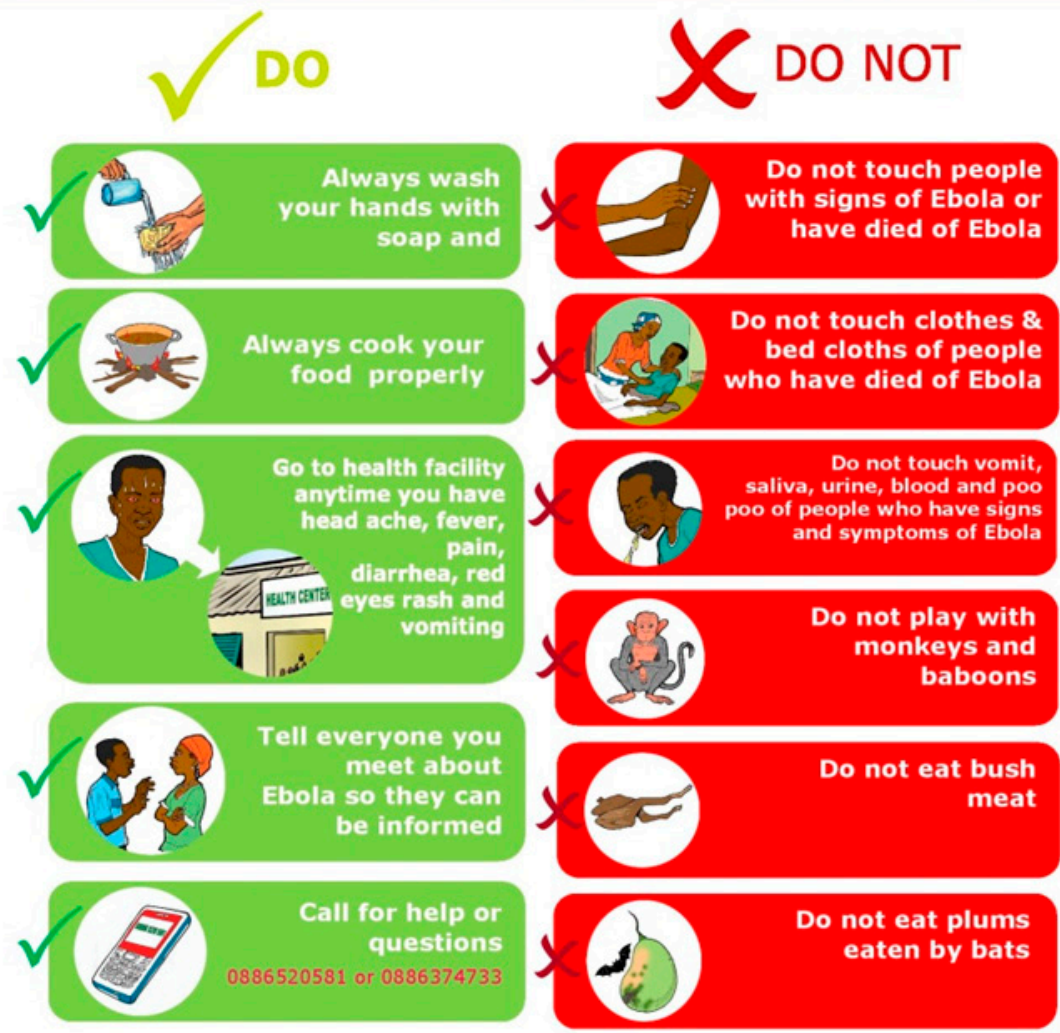


Figure 5: Poster on Ebola Virus Used with Permission from UNICEF.

\section{PROTECT YOURSELF \\ PROTECT YOUR FAMILY \\ PROTECT YOUR COMMUNITY \\ from the Ebola virus}

IF YOU HAVE HEAD ACHE, FEVER, PAIN, DIARRHEA, RED EYES, RASH AND VOMITING, DO THESE THINGS

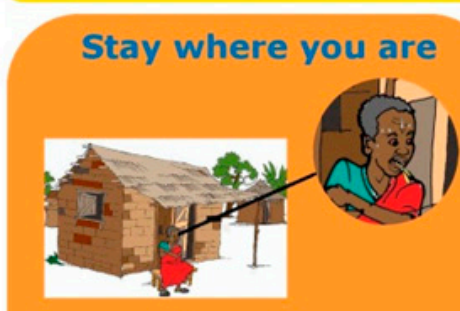

Don't put your family \& community in danger - don't go around others

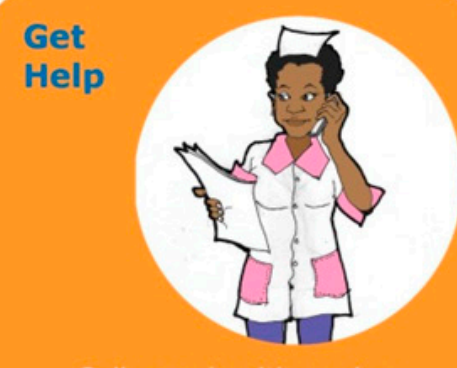

Call your health worker

\section{Cooperate with Health Workers}

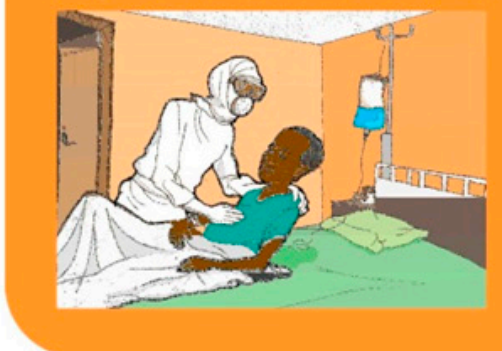

People who care for you must wear gloves, rubber boots, masks, coats \& goggles

Listen to health workers - they know best how to help you

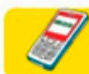

CALL FOR HELP OR QUESTIONS 0886520581 or 0886374733

Let's stop the spread of Ebola together

good resource in educating the people about the do's and don'ts in the spread of EVD.

\section{Community-Government Collaboration Level:} The Governments of the three most affected countries should consider building memorials in each of the districts affected. Cultural burial practices in the affected countries are deeply rooted and family members feel that they would no longer be able to connect to their dead, loved ones if they are buried in mass graves [69]. The memorials should befit the many lives that have been lost to the EVD. These memorials would serve as a way for the people to get a closure on the loss of their loved ones. However, before building these memorials, the Governments should allow the communities to be part of the planning, organizing and implementation so that they can get a sense of ownership and closure [66]. 
United Nations: The United Nations should engage with states that are deficient in their contributions to the support efforts. While giving incentives to states that contribute might not be appropriate, The United Nations can develop methods that would make reluctant states to become more supportive.

EVD Information Dissemination Level: The media has been disproportionally rife with reporting on the numbers of fatalities than on the survivors. We seem to hear only the somber number of fatalities by the WHO. While being honest about the disease, there should be leverage in the communication about the number of fatalities and the number of survivors in order to diminish the fear perpetuated by the EVD.

\section{Conclusion}

This paper has highlighted the societal role in the spread of EVD through stigmatization. The cultural explanations of different diseases were examined. Several factors that have contributed to EVD stigmatization were identified. Some factors like improved sanitation can be initiated at the individual level but some factors like creating a closure for the families of those that died from EVD would need assistance from the Governments of the affected countries.

Provision of basic amenities like water, refuse disposal and toilets should be given a priority by the governments to enable the practice of proper personal hygiene. The Governments of the affected countries should implement efforts to win back the trust of the citizens. There should be leverage in news reporting on EVD. Health education and counselling of communities associated with EVD survivors should also be implemented. Distance education should only be considered as an option for schools if the resources for distance education are available. Although EVD is a preventable disease and there is presently no licensed cure for the diseases, community efforts aimed at reducing the burden of EVD stigmatization would go a long way in the control and prevention of EVD.

\section{Conflicts of Interest}

The author has no conflict of interest.

\section{Acknowledgements}

I would like to acknowledge Virginia Polytechnic Institute and State University's Open Access Subvention Fund (OASF) in my manuscript and UNICEF for permission to use the posters in Figures 1, 4 and $\mathbf{5}$. 


\section{References}

1. Geisbert TW, Jahrling PB. Exotic emerging viral diseases: progress and challenges. Nature medicine. 2004; 10: S110-S21.

2. Paessler S, Walker DH. Pathogenesis of the viral hemorrhagic fevers. Annual review of pathology. 2013; 8: 411- 40.

3. Kiley M, Bowen E, Eddy G, Isaäcson M, Johnson K, McCormick J, et al. Filoviridae: a taxonomic home for Marburg and Ebola viruses? Intervirology. 1982; 18(1-2): 24-32.

4. Peters $C$, Jahrling $P$, Khan $A$. Patients infected with highhazard viruses: scientific basis for infection control: Springer; 1996. Available online: http://link.springer.com/ chapter/10.1007\%2F978-3-7091-7482-1_13\#page-1 (accessed on 24 December, 2014).

5. Biosafety in Microbiological and Biomedical Laboratories 5th Edition pp. 1-8, pp. 24-26; CDC, USDHHS, NIH. Available online: http://www.cdc.gov/biosafety/publications/bmbl5/BMBL.pdf (accessed on 23 December, 2014).

6. Peters $C$, Jahrling P, Khan A. Patients infected with high-hazard viruses: scientific basis for infection control: Arch Virol (1996) [Suppl] 11: 141-168.

7. Martines RB, Ng DL, Greer PW, Rollin PE, Zaki SR. Tissue and cellular tropism, pathology and pathogenesis of Ebola and Marburg viruses. J Pathol. 2015; 235(2): 153-74.

8. Negredo A, Palacios G, Vázquez-Morón S, González F, Dopazo $\mathrm{H}$, Molero $\mathrm{F}$, et al. Discovery of an ebolavirus-like filovirus in europe. PLoS pathogens. 2011; 7(10): e1002304

9. Baize S, Pannetier D, Oestereich L, Rieger T, Koivogui L, Magassouba NF, et al. Emergence of Zaire Ebola Virus Disease in Guinea. N Engl J Med. 2014; 371(15): 1418-25.

10. Pigott DM, Golding N, Mylne A, Huang Z, Henry AJ, Weiss DJ, et al. Mapping the zoonotic niche of Ebola virus disease in Africa. eLife. 2014;3:e04395. Available online: http://dx.doi. org/10.7554/eLife.04395 Available online: http://elifesciences. org/content/3/e04395 (accessed on 23 December, 2014).

11. Maganga GD, Kapetshi J, Berthet N, Ilunga BK, Kingebeni PM, Mondonge $\mathrm{V}$, et al. Ebola virus disease in the Democratic Republic of Congo. N Engl J Med. 2014. DOI: 10.1056/NEJMoa1411099

12. Feldmann H. Ebola-A Growing Threat? N Engl J Med 2014; 371: 1375-1378,October 9, 2014 DOI: 10.1056/NEJMp1405314. Available online: http://www.nejm.org/doi/full/10.1056/ NEJMp1405314 (accessed on 23 October, 2014).

13. Report on an International Commission. Ebola haemorrhagic fever in Sudan, 1976. Bulletin of the World Health Organization. 1978; 56(2): 247. Available online: http://europepmc.org/ backend/ptpmcrender.fcgi?accid=PMC2395561\&blobtype $=$ pdf (accessed on 25 December, 2014).

14. Report of an International Commission. Ebola haemorrhagic fever in Zaire, 1976. Bulletin of the World Health Organization 1978; 56(2): 271-293. Available online: http://www.ncbi.nlm. nih.gov.ezproxy.lib.vt.edu/pmc/articles/PMC2395567/pdf/ bullwho00439-0113.pdf (accessed on 25 December, 2014).
15. Feldmann H, Geisbert TW. Ebola haemorrhagic fever. The Lancet. 2011; 377(9768): 849-62. Available online: doi: 10.1016/ s0140-6736(10)60667-8 (accessed on 23 December, 2014).

16. Le Guenno, B., Formenty, P., Wyers, M., Gounon, P., Walker, F., \& Boesch, C. (1995). Isolation and partial characterisation of a new strain of Ebola virus. The lancet, 345 (8960), 1271-1274.

17. Ng S, Basta N, Cowling B. Association between temperature, humidity and ebolavirus disease outbreaks in Africa, 1976 to 2014. Euro Surveill. 2014; 19(35): pii=20892. Available online: http:// www.eurosurveillance.org/ViewArticle. aspx?Articleld=20892 (accessed on 21 December, 2014).

18. Samaranayake L, Peiris J, Scully C. Ebola virus infection: an overview. British dental journal. 1996;180(7):264-6.

19. WHO. Sierra Leone: for Ebola survivors the pain goes on. Geneva: WHO, 2014. Available online: http://www.who.int/ features/2014/post-ebola-syndrome/en/ (accessed on 30 October, 2014).

20. Goffman E Stigma: Notes on the management of spoiled identity. Englewood Cliffs, NJ: Prentice Hall. 1963.

21. Weiss MG Ramakrishna J Somma D. Health-related stigma: rethinking concepts and interventions. Psychol Health \& Med. 2006; 11(3): 277-87.

22. Piot P. No time to lose: A life in pursuit of deadly viruses: WW Norton \& Company, London 2012.

23. Varkevisser CM, Lever $P$, Alubo O, Burathoki K, Idawani C, Moreira TM, et al. Gender and leprosy: case studies in Indonesia, Nigeria, Nepal and Brazil. Lepr Rev. 2009; 80(1): 65-76.

24. Nurge E. Etiology of illness in Guinhangdan. American Anthropologist. 1958; 60(6): 1158-72. Available online: http:// onlinelibrary.wiley.com/doi/10.1525/aa.1958.60.6.02a00100/ pdf (accessed on 21 December, 2014).

25. Opala J, Boillot F. Leprosy among the Limba: illness and healing in the context of world view. Soc Sci Med. 1996; 42(1): 3-19.

26. Chapple A, Ziebland S, McPherson A. Stigma, shame, and blame experienced by patients with lung cancer: qualitative study.BMJ. 2004;328(7454):1470. Available online: http://www. bmj.com/content/early/2003/12/31/bmj.38111.639734.7C. full.pdf+html (accessed on 20 December, 2014). doi: 10.1136/ bmj.38111.639734.7C

27. Marlow LA, Waller J, Wardle J. Variation in blame attributions across different cancer types. Cancer Epidemiol Biomarkers Prev. 2010; 19(7): 1799-805.

28. Bloom JR, Hayes WA, Saunders F, Flatt S. Cancer awareness and secondary prevention practices in black Americans: implications for intervention. Family \& Community Health. 1987;10(3):19-30.

29. Brieger WR, Oshiname FO, Ososanya OO. Stigma associated with onchocercal skin disease among those affected near the Ofiki and Oyan Rivers in western Nigeria. Soc Science \& Medicine. 1998; 47(7): 841-52.

30. Bond $V$, Nyblade $L$. The importance of addressing the unfolding TB-HIV stigma in high HIV prevalence settings. Journal of Community \& Applied Social Psychology. 2006;16(6):452-61. 
31. Edginton M, Sekatane C, Goldstein S. Patients' beliefs: do they affect tuberculosis control? A study in a rural district of South Africa. Int J Tuberc Lung Dis. 2002; 6(12): 1075-82

32. Gussow Z, Tracy GS. Status, ideology, and adaptation to stigmatized illness: A study of leprosy. Human Organization. 1968; 27(4): 316-25.

33. Cookson R, Rhodes S. Leprosy: India's hidden disease. The Guardian. 24 March 2011. Available online: http://www. theguardian.com/lifeandstyle/2011/mar/24/leprosy-indiahidden-disease (accessed on 28 October, 2014).

34. Walsh F. The hidden suffering of India's lepers. BBC. 31 Mar 2007. Available online: http://news.bbc.co.uk/2/hi/programmes/ from_our_own_correspondent/6510503.stm (accessed on 28 October, 2014).

35. Sato H, Frantz JE. Termination of the leprosy isolation policy in the US and Japan: Science, policy changes, and the garbage can model. BMC Int Health Hum Rights. 2005; 5(1): 3.

36. CDC. Questions and answers on the executive order adding potentially pandemic influenza viruses to the list of quarantinable diseases. CDC. 2014. Available online: http://www.cdc.gov/ quarantine/qa-executive-order-pandemic-list-quarantinablediseases.html (accessed on 28 October, 2014).

37.US. Government Publishing Office. Federal Register. Department of Health and Human services. Centers for Disease Control and Prevention. 42 CFR Part 34. [Docket No. CDC-2009-0003]. RIN 0920-AA26. Medical Examination of Aliens- Removal of Human Immunodeficiency Virus (HIV) Infection from Definition of Communicable Disease of Public Health Significance. Available online: http://www.gpo.gov/fdsys/pkg/FR-2009-11-02/pdf/E926337.pdf (accessed on January 3, 2014).

38. Telegraph. Swine flu: Diplomatic row after China quarantines healthy Mexicans. The Telegraph. May 3, 2009. Available online: http://www.telegraph.co.uk/health/swine-flu/5268156/Swineflu-Diplomatic-row-after-China-quarantines-healthy -Mexicans. html (accessed on 25 October, 2014).

39. Shrestha SS, Swerdlow D L, Borse RH, et al. Estimating the burden of 2009 pandemic influenza A (H1N1) in the United States (April 2009-April 2010). 2011 Clin Infect Dis, 52, 75-82.

40. WHO. Global Alert and Response;(GAR) update 49 - SARS case fatality ratio, incubation period. Geneva: WHO, 2003. Available online: http://www.who.int/csr/sarsarchive/2003_05_07a/en/ (accessed on 23 October, 2014).

41. WHO Global Alert Response (GAR) Ebola response RoadmapSituation report 24 December 2014. Available online: http:// apps.who.int/ebolaweb/sitreps/20141224/20141224.pdf (accessed on 24 December 2014).

42. WHO Ebola response team. Ebola Virus Disease in West Africa - The First 9 Months of the Epidemic and Forward Projections. N Engl J Med 2014; 371(16): 1481-1495. Available online: http:// www.nejm.org/doi/pdf/10.1056/NEJMoa1411100 (accessed on 13 October, 2014)
43. Gilman SL. Disease and stigma. The Lancet. 1999; 354: SIV15.

44. CDC. H1N1 (originally referred to as Swine Flu). CDC. 2014. Available online: http://www.flu.gov/about_the_flu/h1n1/ (accessed on 28 October, 2014).

45. WHO Ebola virus disease, West Africa - update 28 August 2014. Available online: http://www.afro.who.int/en/clustersa-programmes/dpc/epidemic-a-pandemic-alert-and-response/ outbreak-news/4264-ebola-virus-disease-update-west-africa28-august-2014.html (accessed on 24 December, 2014).

46. Bausch DG, Schwarz L. Outbreak of Ebola virus disease in Guinea: where ecology meets economy. PLoS neglected tropical diseases. 2014;8(7):e3056. doi: 10.1371/journal.pntd.0003056

47.Lamontagne $F$, Clément $C$, Fletcher $T$, Jacob ST, Fischer WA, Fowler RA. Doing Today's Work Superbly Well - Treating Ebola with Current Tools. N Engl J Med. 2014; 371(17): 1565-6.

48. Piot P, Muyembe J-J, Edmunds WJ. Ebola in West Africa: from disease outbreak to humanitarian crisis. Lancet Infect Dis. 2014; 14(11): 1034-5.

49. WHO Infection prevention and control of epidemic- and pandemic-prone acute respiratory diseases in health care; ARDs that may constitute a public health emergency of international concern covered in the current document. Available online: http://www.who.int/csr/resources/publications/WHO_CDS_ EPR_2007_6c.pdf?ua=1 (accessed on 24 December, 2014).

50. WHO Situation Report 1 Ebola Virus Disease, Guinea, 28 March 2014. Available online: http://www.afro.who.int/en/clustersa-programmes/dpc/epidemic-a-pandemic-alert-and-response/ sitreps/4070-sitrep-1-ebola-guinea-28-march-2014.html (accessed on 28 January 2014).

51. Ebola Virus Disease Outbreak Response Plan in West Africa; World Health Organization and the Governments of Guinea, Liberia, and Sierra Leone p.3. Available online: http://www. who.int/csr/disease/ebola/evd-outbreak-response-plan-westafrica-2014.pdf (accessed on 1 January 2015).

52. Hewlett B, Epelboin A, Hewlett B, Formenty P. Anthropologie médicale. Bull Soc Pathol Exot. 2005; 98(3): 230-6.

53. Hewlett BS, Amola RP. Cultural contexts of Ebola in Northern Uganda. Emerg Infect Dis, 2003;9(10):1242.

54. Hewlett B L, Hewlett BS. Providing care and facing death: nursing during Ebola outbreaks in Central Africa. J Nurs, 2005; 16, 289-297.

55. BBC. Ebola Outbreak: Guinea health team killed. 18 Sept 2014. Available online: http://www.bbc.com/news/worldafrica-29256443 (accessed on 28 October, 2014).

56. Kinsman J, A time of fear: local, national, and international responses to a large Ebola outbreak in Uganda. Glob Health. 2012; 8: 15. 
57. Okware S, Omaswa F, Zaramba A, et al. An outbreak of Ebola in Uganda. Trop Med Int Health, 2002; 7, 1068 - 1075.

58. BBC. Africa Cup of Nations: Morocco will not host finals over Ebola fears. Available online: http://www.bbc.com/sport/0/ football/30004279 (accessed on 30 January, 2015).

59. WHO. Global Alert and Response (GAR): Summary of probable SARS cases with onset of illness from 1 November 2002 to 31 July 2003. Geneva: WHO, 2013. Available online: http://www. who.int/csr/sars/country/table2004_04_21/en/ (accessed on 28 October, 2014).

60. WHO. Sierra Leone: for Ebola survivors the pain goes on. Geneva: WHO, 2014. Available online: http://www.who.int/ features/2014/post-ebola-syndrome/en/ (accessed on 30 October, 2014).

61. UNDP Human Development Reports. Table 1: Human Development Index and its components. 2014. Available online: http://hdr.undp.org/en/content/table-1-human-developmentindex-and-its-components (accessed on 13 October, 2014).

62. Lamontagne F, Clément $C$, Fletcher $T$, Jacob ST, Fischer WA, Fowler RA. Doing Today's Work Superbly Well — Treating Ebola with Current Tools. N Engl J Med 2014; 371(17): 1565-6.

63. Gostin LO, Friedman EA. Ebola: a crisis in global health leadership. The Lancet. 2014; 384(9951): 1323-5.

64. Ebola: Three reasons why most US patients have survived. Available online: http://www.cbsnews.com/news/ebola-threereasons-most-us-patients-survived/ (accessed on 25 December, 2014).

65. Reaves EJ, Mabande LG, Thoroughman DA, Arwady MA, Montgomery JM. Control of Ebola virus disease-Firestone District, Liberia, 2014. MMWR. 2014; 63: 959-65.

66. Obilade TT ,The Political Economy of the Ebola Virus Disease (EVD); Taking Individual and Community Ownership in the Prevention and Control of EVD. Healthcare 2015, 3, 36-49; doi:10.3390/healthcare3010036. Available online: http://www. mdpi.com/2227-9032/3/1/36 (accessed on 30 January, 2015).

67.WHO, WHO Declares End of Ebola Outbreak in the Democratic Republic of Congo. Available online: http://www.who.int/ mediacentre/news/statements/2014/drc-ends-ebola/en/ (accessed on 28 December 2014).

68. Obilade TT, Instructional technology and distance education in Nigeria; Historical background and a critical appraisal Distance Learning. 2013 10(1): 25 -29.

69. BBC Why Ebola is so dangerous. 8 Oct 2014. http://www.bbc. com/news/world-africa-26835233 (accessed on 30 October, 2014).

\section{Comment on this article:}

\section{$9 B$ in $8+S$}

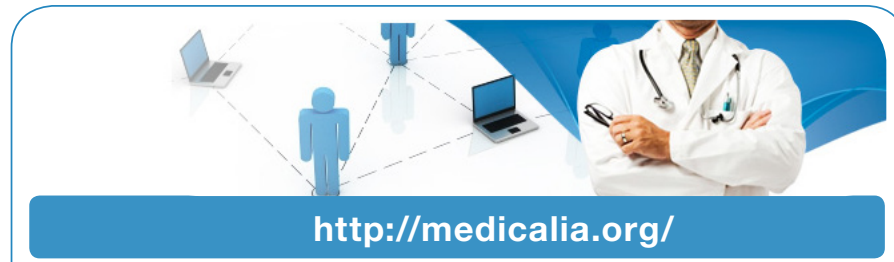

Where Doctors exchange clinical experiences, review their cases and share clinical knowledge. You can also access lots of medical publications for free. Join Now!

\section{Publish with iMedPub \\ http://www.imed.pub}

International Archives of Medicine is an open access journal publishing articles encompassing all aspects of medical science and clinical practice. IAM is considered a megajournal with independent sections on all areas of medicine. IAM is a really international journal with authors and board members from all around the world. The journal is widely indexed and classified Q1 in category Medicine. 